\title{
Situation Analysis of Healthcare Service Delivery using Geographically Weighted Regression: (A Case Study of Sironko District, Eastern Uganda)
}

\author{
Joel Kitutu $^{1}$, Lydia Mazzi Kayondo ${ }^{2}$, Moses Musinguzi ${ }^{3}$ \\ 1, 23 Department of Geomatics and Land Management, School of the Built Environment, College of \\ Engineering, Design, Art and Technology, Makerere University, Kampala, Uganda, \\ jkitutu2000@gmail.com, +256785133103
}

DOI: http://dx.doi.org/10.4314/sajg.v7i1.6

\begin{abstract}
Geography plays an important role in planning and allocation of healthcare resources for an effective and efficient health system. Lack of statistical information analyzed using geostatistical tools then becomes a major bottleneck to proper planning and policy formulation in healthcare delivery. This study sought to compare existing health staffing, funding and medical supplies data given minimal national healthcare package, spatially explore the relationship between health service utilization and gaps in resource allocation, and to develop propositions to support the health policy. Facility survey and secondary data collection from the District Health Office and the Ministry of Health were utilized. Geographically Weighted Regression was used to spatially explore the relationships between Out-patient department attendance and gaps in health funding, staffing and stock-out days for essential drugs in health facilities. Global Moran's I test was performed on the standard residuals to statistically test for their randomness. The analysis yielded local parameter estimates which were mapped to reveal the spatial variation of the relationships. There was strong influence of facility allocation gap in the North West diminishing towards South East, Strong negative influence of the staffing gap in the South West diminishing eastwards, and High influence of StockOut days in the South compared to the South West. Basing on the observations, the study proposed increased health vote while revising allocation based more on need other than solely on budgetary allocation of funds, increased staffing and providence of incentives for disadvantaged areas, and monitoring of drug supply and dispensing at health centres.
\end{abstract}

\section{Introduction}

According to the World Health Organization (WHO), health services include all services dealing with the diagnosis and treatment of disease, or the promotion, maintenance and restoration of health. Like all other human needs, the provision of equitable and effective health services is a fundamental contributor to the development at global, regional, national and sub national levels. Since only a healthy population can lead to sustainable development, the world community formulated the Millennium Development Goals (MDGs) and the more recent Sustainable Development Goals (SDGs) to address among others, health related challenges. MDGs 4, 5 and 6 are all directly targeting health concerns that need to be appropriately addressed so as to ensure a healthy and enduring 
population. In relation to MDGs on health, SDG 3 aims to "ensure healthy lives and promote wellbeing for all at all ages”. Health services are thus a major area of concern both globally and locally. However, the provision of these services has met innumerable challenges ranging from poor funding, inadequate medical supplies, and poor infrastructure to low staffing among others. WHO (2010) stipulates that a good health system should have services directly and permanently accessible without undue barriers of cost, and that there should be a minimum wastage of resources through good management of the services. However, nearly all the continents of the world are grappling with poor health services despite the continued effort geared towards ensuring equitable and sustainable health systems for all people.

In Uganda, the Health Sector Strategic Plans (HSSP I and II) were developed as crucial instruments to support equitable health service delivery. The Health Policy was equally developed to support the provision of minimum health care package deemed equitable for all Ugandans. However, despite these efforts, many people in Uganda are still lacking proper health services as witnessed in the Uganda Annual Health Sector Performance Report for Financial Year 2014/15 (Uganda Ministry of Health 2015).

The health budget in Uganda is grossly inadequate and is experiencing severe pressure owing to the creation of more local governments and expansion of the health infrastructure. Uganda like many other African countries is still way below the agreed position in the Abuja Declaration of at least 15\% of the National Budget for health (WHO, 2000). The Ministry of Finance, planning and Economic Development (2013) notes that for a long time since the declaration, the allocation to health in Uganda has stagnated at an average of $7 \%$. The Ministry of Health has endlessly lobbied for increased budgetary allocation to the health sector but a major bottleneck has been a lack of convincing justification for the increase.

Geographical analysis of health variables has more recently provided crucial evidence to guide health policies (Alka, 2012). Amer (2007) points out the need to look at socio economic performance indicators with a spatial dimension so as to ensure more equitable and efficient health planning. Geostatistical analyses have increasingly been used in health research as can be seen in the work of Hazrin et al. (2013) where Geographically Weighted Regression (GWR) was employed to analyze the requirement of health clinic in a sub-district by exploring the various spatial relationships that existed among the variables used. With increasing computational power and visualization capabilities in the GIS, the exploration of spatial relationships among georeferenced data has been made possible (Anselin, 1995). This study applies GWR technique developed by Brunsdon et al. (1996) in health service delivery seeking to test for, and explore local spatial variations among health variables and to reveal the underlying patterns (Fotheringham et al., 2001).

The findings target technical and high level officers working on resource allocation, service planning and health policy formulation at national, sub regional and local levels to facilitate actions that optimize health services and maximize the use of available resources in the health sector in Sironko district. 


\section{Study Area}

The study area covers Sironko district which is one of the five districts that make up Bugisu subregion in Eastern Uganda. Figure 1 shows the location of the study area in Uganda. Sironko district stretches from $34.162^{\circ}$ to $34.472^{\circ}$ longitude and from $1.0802^{\circ}$ to $1.2948^{\circ}$ latitude. On the eastern side, the district touches the Wagagai peak - the highest point of Mount Elgon.

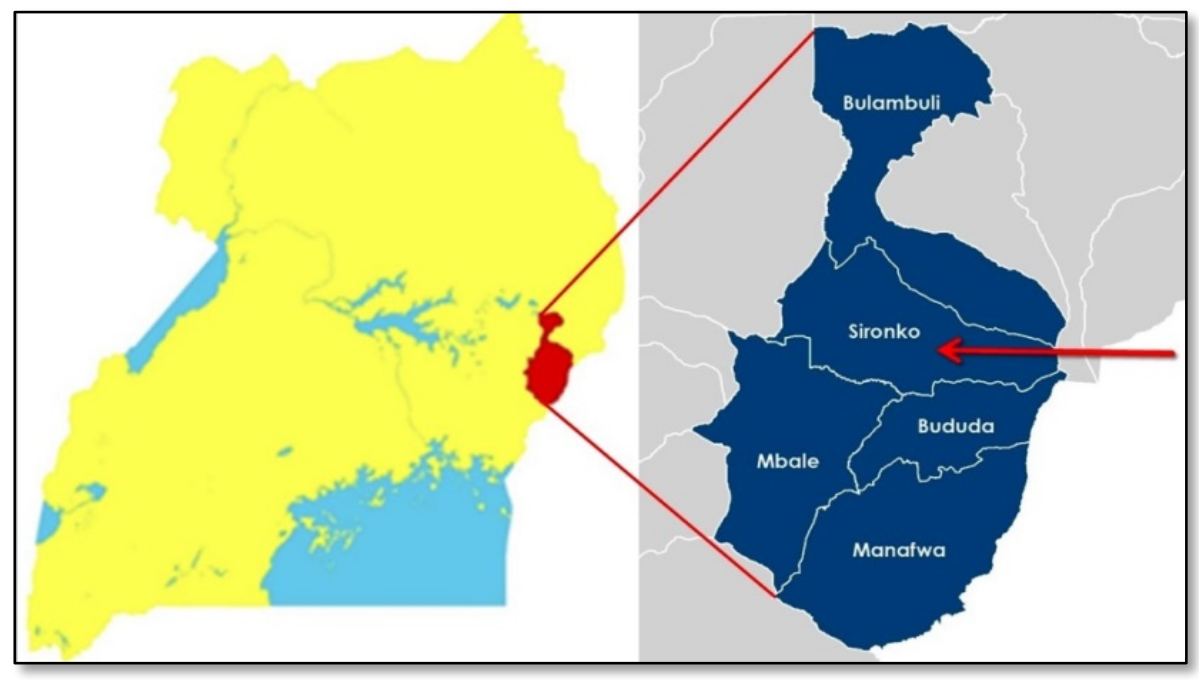

Figure 1. Location of the study area in Uganda

The district has over the last fourteen years grown from 10 to 21 sub-counties as a result of the government's strategy of taking services closer to the people. Within this same time of growth, the land area has remained 372.179sqkm with an increase in population from 185,819 in 2002 to 246,636 in 2014 (i.e. 60,817). By June, 2016, the district had 28 major health units that support the delivery of healthcare. These comprised of 2 Health centre IVs, 12 government and 3 Non-government Health centre IIIs, and 8 government and 3 Non-government Health centre IIs. This study included an extra two health units namely; St. Mary’s Medical Centre and Tropical Medical and Maternity Centre to make the number of the health units sufficient for regression analysis. Figure 2 shows the location of health centres against population density at sub-county level in Sironko district.

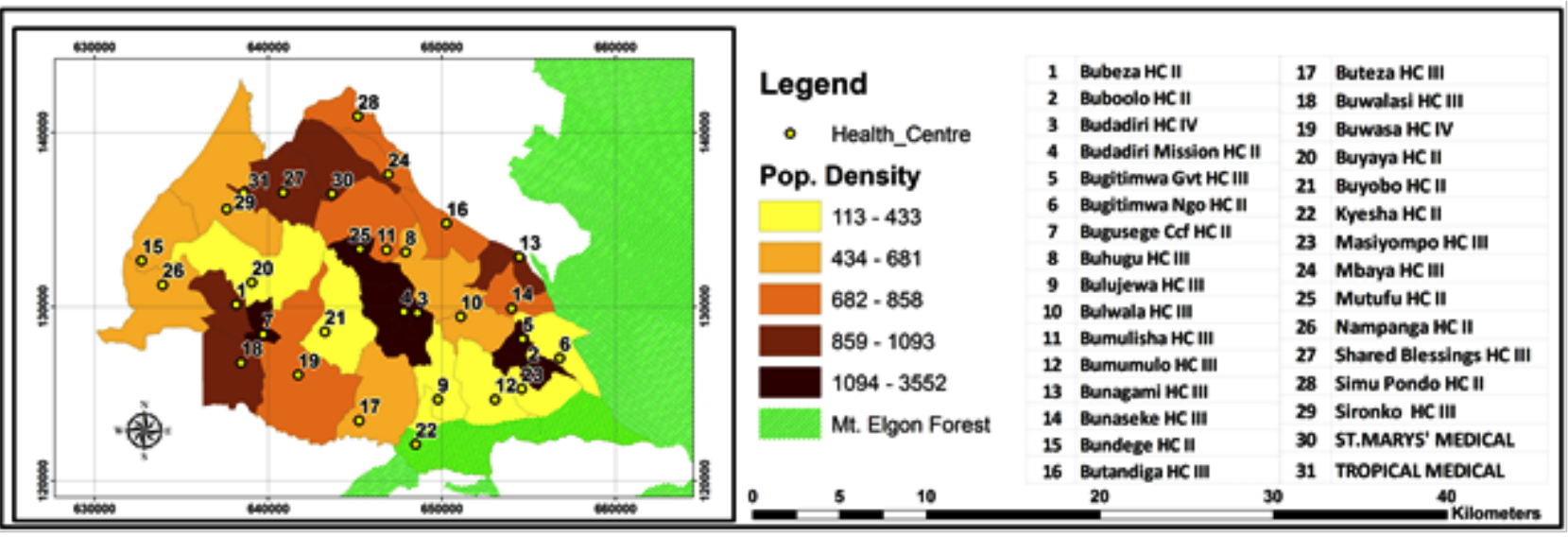

Figure 2. Location of health centres against population density in Sironko district 


\section{Materials and Methods}

\subsection{Data}

Health Indicators data was collected and compiled from the District Health Office and the Demographic and Health Information System (DHIS2) portal at the Ministry of Health website. These data were checked against data captured during facility survey on selected health centres to authenticate their accuracy. The GPS coordinates for the health centres were obtained from the GIS division - Uganda Bureau of Statistics, but were also verified during the facility survey. Several indicators were considered whose actual figures would be compared with those planned by the government so as to measure performance of the health sector in the district. Specific data collected for the regression analysis included figures for out-patient department (OPD) attendance, staffing, funding and stock-out days for essential drugs for the year 2015. The Out-patient Department attendance (OPD2015) was used as the dependent variable. Two explanatory variables namely; Staffing gap (STFGAP2015) and Funding gap (FAG) were computed as differences between the actual and minimum planned figures by the government. The third explanatory variable used was Highest Stock-out days for an essential drug (SODHIGHEST). The geographical area served by each health centre (i.e. Catchment area) was defined using the parish shapefile for the district. This parish shapefile is a GIS vector layer of the second lowest administrative units in Uganda. Data for the indicators was then attached to the shapefile of the health centre catchment areas, and the shapefile used for analysis.

\subsection{Spatial Analysis}

\subsubsection{Spatial Regression: Geographically Weighted Regression}

The standard application of regression involves linking a dependent variable to a set of independent / explanatory variables with one of the main outputs of regression being the estimation of a parameter that links each of the independent variable to the dependent variable (Sinaga et al., 2016). Developing an efficient framework for the regression model requires that there are set assumptions, the Kernel Weighting Function is established, the choice of the bandwidth is made and most importantly, model diagnostic tests are performed to ensure that the parameter estimates of the resultant regression model are not biased (Pirdavani et al., 2014; Sinaga et al., 2016). According to Rhee et al (2016), generalized linear models (GLMs) are conventional linear regression models for a continuous response variable given a set of continuous and/or categorical predictors. Examples of GLMs include Auto-logistic models, Conditional Auto-regression (CAR) models, Simultaneous Auto-regression (SAR) models, spatial error models (SEM), Generalized Estimating Equation (GEE) models, Full-Bayesian Spatial models, Ordinary Least Squares(OLS), Bayesian Poisson-lognormal models, Poisson models and Negative Binomial (NB) models. According to Fotheringham et al (2002) and Nakaya et al (2005), the weakness of GLMs of overlooking "spatial nonstationarity / heterogeneity” can be accounted for by GWR models as these can be used to develop local models. 
Table 1. Comparison of fixed kernel and adaptive kernel GWR models

\begin{tabular}{|c|c|c|c|c|c|c|c|c|c|}
\hline \multicolumn{4}{|c|}{ GWR Model 1 (Fixed Kernel) } & \multicolumn{4}{|c|}{$\begin{array}{l}\text { GWR Model } 2 \text { (Adaptive kernel) } \\
\text { (Optimal - determined by the GWR tool) }\end{array}$} & \multicolumn{2}{|c|}{ Analysis } \\
\hline No & $\begin{array}{l}\text { Variable } \\
\text { name }\end{array}$ & Variable & Definition & No & $\begin{array}{c}\text { Variable } \\
\text { name }\end{array}$ & Variable & Definition & Interpretation & Better \\
\hline 1. & Bandwidth & 5000 & & 1. & Neighbours & 31 & & & \\
\hline 2. & $\begin{array}{l}\text { Residual } \\
\text { squares }\end{array}$ & $2.3 \mathrm{E} 8$ & & 2. & $\begin{array}{l}\text { Residual } \\
\text { squares }\end{array}$ & 5.5E8 & & $\begin{array}{c}\text { Smaller } \\
= \\
\text { Closer Fit }\end{array}$ & 1 \\
\hline 3. & $\begin{array}{l}\text { Effective } \\
\text { number }\end{array}$ & 19 & & 3. & $\begin{array}{l}\text { Effective } \\
\text { number }\end{array}$ & 8 & & $\begin{array}{c}\text { Larger } \\
= \\
\text { Small Bias, } \\
\text { Large Variance }\end{array}$ & 1 \\
\hline 4. & Sigma & 4391 & & 4. & Sigma & 4864 & & $\begin{array}{c}\text { Smaller } \\
= \\
\text { Better }\end{array}$ & 1 \\
\hline 5. & AICc & 653 & & 5. & AICc & 626 & & $\begin{array}{c}\text { Smaller } \\
= \\
\text { Better Model } \\
\text { Performance } \\
\end{array}$ & 2 \\
\hline 6. & R2 & 0.90 & & 6. & R2 & 0.76 & & $\begin{array}{c}\text { Larger }=\text { Better } \\
\text { Fit }\end{array}$ & 1 \\
\hline 7. & R2adjusted & 0.75 & & 7. & R2adjusted & 0.69 & & $\begin{array}{c}\text { Larger } \\
= \\
\text { Better Fit } \\
\end{array}$ & 1 \\
\hline 8. & $\begin{array}{l}\text { Dependent } \\
\quad \text { Field }\end{array}$ & 0 & OPD 2015 & 8. & $\begin{array}{l}\text { Dependent } \\
\quad \text { Field }\end{array}$ & 0 & OPD 2015 & $\begin{array}{l}\text { Out Patient } \\
\text { Dept. } \\
\text { Utilization }\end{array}$ & \\
\hline 9. & $\begin{array}{l}\text { Independ. } \\
\text { Field }\end{array}$ & 1 & FA GAP & 9. & $\begin{array}{l}\text { Independ. } \\
\text { Field }\end{array}$ & 1 & FA GAP & $\begin{array}{c}\text { Facility } \\
\text { Allocation Gap }\end{array}$ & \\
\hline 10. & $\begin{array}{l}\text { Independ. } \\
\text { Field }\end{array}$ & 2 & $\begin{array}{l}\text { STFGAP } \\
2015\end{array}$ & 10. & $\begin{array}{l}\text { Independ. } \\
\text { Field }\end{array}$ & 2 & $\begin{array}{l}\text { STFGAP } \\
2015\end{array}$ & Staffing Gap & \\
\hline 11. & $\begin{array}{l}\text { Independ. } \\
\text { Field }\end{array}$ & 3 & $\begin{array}{l}\text { SOD } \\
\text { Highest }\end{array}$ & 11. & $\begin{array}{l}\text { Independ. } \\
\text { Field }\end{array}$ & 3 & $\begin{array}{l}\text { SOD } \\
\text { Highest }\end{array}$ & $\begin{array}{l}\text { Highest Stock } \\
\text { Out Days }\end{array}$ & \\
\hline
\end{tabular}

GWR has been identified as one of the geostatistical methods that should be promoted in health studies in light of the locality of health outcomes (Young et al., 2010). Matthews et al (2012) argued that GWR can potentially make significant contributions to health research, such as allowing researchers to better understand the etiology and spatial processes, offering informative results beyond global models to facilitate place- specific health policy formation, and enabling scholars to explore questions that cannot be answered with traditional (global) analytical models. GWR was preferred to Ordinary Least Squares (OLS) for regression as the latter produces a global model which doesn't accommodate spatial non-stationarity of georeferenced data, (Lin et al., 2011 and Pirdavani et al., 2014). OPD2015 was used as the dependent variable for the regression analysis performed in ArcMap 10.2.2 using the GWR tool. Two regression models were developed for comparison; one using adaptive method of kernel where the computer was allowed to choose the optimal bandwidth for the distance or number of neighbors. An adaptive kernel function looks at an adaptive number neighbours and the influence of these neighbours decays a Gaussian distribution so that closer observations have more weight (Homan et al, 2016). The other model employed a fixed kernel distance of $5 \mathrm{~km}$ to determine the neighbors to be used in the regression computation. 5km kernel 
distance was arrived at after iteration with increasing bandwidth distance from $1 \mathrm{~km}$ to $10 \mathrm{~km}$, and checking the regression diagnostics to ensure that the model passes and performs best. Three assumptions suggested by Chi et al (2016), Pirdavani et al (2014) and Sinaga et al (2016) were observed to enable testing of the goodness of fit of the model and hence model, namely; [1] There must be nonstationary relationships between the dependent variable and the selected spatial variable factors. However, a linear relationship is possible but can be addressed through a different choice of the model, [2] The variance of error terms should be constant across observations (also known as homoskedasticity), and [3] The error terms are not auto-correlated and any one residual is not correlated with any other residual in the study area. The main check was the R-squared (ranging from $0.0(0 \%)$ to $1.0(100 \%)$ ) with the higher value indicating the better model in terms of performance. Table 1 is a comparison of the two main models.

\subsubsection{Spatial Autocorrelation: Global Moran's I}

Using 0.1 level of significance, the Global Moran's I tool was run on the standard residuals to compute the spatial autocorrelation for the over and under-predictions of the regression model. This was done to examine their spatial distribution and thus check for clustering.

\subsubsection{Analyzing Spatial Patterns: Spatial Relationships}

The dependent variable - OPD2015 was mapped against the independent variables of gaps in funding, staffing and highest stock-out days. The observations and their interpretation were recorded. The coefficients for the three predictor variables from the regression model were mapped to reveal the spatial patterns of their influences.

\section{Results and Discussion}

\subsection{Performance Indicators}

Table 2 shows health indicators whose data were collected in 2014/2015 financial year, their scores against the set targets and their performance in percentages. From the Table, it can be observed that Sironko district performed best in indicator 4: HIV testing in children born to HIV positive Mothers, and worst in indicator 7: 4th Antenatal care visit. Indicator 2: Deliveries in Government \& Private Not for Profit (PNFP) Facilities performed poorly as compared to other indicators. The first four Health Sector Strategic and Investment Plan core indicators are; Maternal Mortality Ratio, Infant Mortality Ratio, Under 5 Mortality rate and Neonatal Mortality Ratio. These are greatly affected by indicators 2 and 7 in table 2. The poor performance of these two indicators (worst performing) signals a dire need for concerted efforts to improve the health system in the district. 
Table 2. Health indicators whose data were collected in 2014/2015 financial year

\begin{tabular}{|c|c|c|c|c|}
\hline & \multicolumn{4}{|c|}{ 2014/15 Performance } \\
\hline & Indicator & Score & Target & Percentage \\
\hline 1 & DPT 3 Coverage & 13.9 & 15 & $92.67 \%$ \\
\hline 2 & Deliveries in Government \& PNFP Facilities & 4.1 & 15 & $27.33 \%$ \\
\hline 3 & OPD per capita & 8.7 & 10 & $87.00 \%$ \\
\hline 4 & $\begin{array}{l}\text { HIV testing in children born to HIV positive } \\
\text { Mothers }\end{array}$ & 10 & 10 & $100.00 \%$ \\
\hline 5 & Latrine Coverage in Households & 7.7 & 10 & $77.00 \%$ \\
\hline 6 & IPT2 & 1.9 & 5 & $38.00 \%$ \\
\hline 7 & ANC 4 & 1.1 & 5 & $22.00 \%$ \\
\hline 8 & TB Success Rate & 4.8 & 5 & $96.00 \%$ \\
\hline 9 & Approved Posts that are filled & 6.2 & 10 & $62.00 \%$ \\
\hline 10 & \%monthly Report Sent on time & 7.1 & 10 & $71.00 \%$ \\
\hline 11 & Medicine Orders Submitted Timely & 4.9 & 5 & $98.00 \%$ \\
\hline 12 & $\%$ of Villages with trained VHTs & 743 & 1284 & $57.87 \%$ \\
\hline 13 & $\begin{array}{l}\text { GOU health expenditures as \% of total government } \\
\text { expenditure }\end{array}$ & 0.07 & 0.1 & $70.00 \%$ \\
\hline
\end{tabular}

\subsection{Regression Variables}

The dependent variable for the regression analysis constituted the number of out-patient department visitations for the year 2015. The three independent variables comprised: the number of stock-out days per health facility and the gaps in both staffing and funding per health facility for the same year. The maps for these variables are shown in figures 3, 4, 5 and 6. In figure 3, there are high out-patient department numbers within the main town area in the North West, and around the other major towns in North Central and Southern part of the district. These are areas of relatively high population. In figure 4, areas around Shared Blessing Health Centre, Buhugu and Masiyopo have high staffing gaps with Sironko, Buwalasi and Buwasa having staffing numbers exceeding the government ceiling. In figure 5, there is a high facility allocation gap in terms of funding in Buwasa, Budadiri and Shared Blessing health centres. In figure 6, areas the North West and North East of the district experienced severe Stock-Out days of at least one essential drug in 2015. 


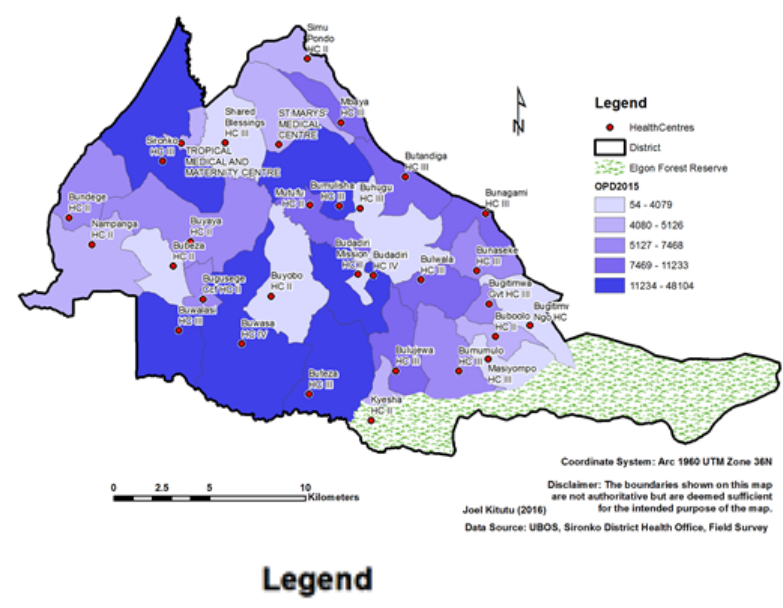

- HealthCentres

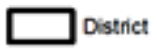

Elgon Forest Reserve OPD2015

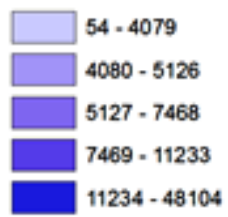

Figure 3. Out-patient Department Numbers

Map of Sironko District Health Facility Staffing Gap

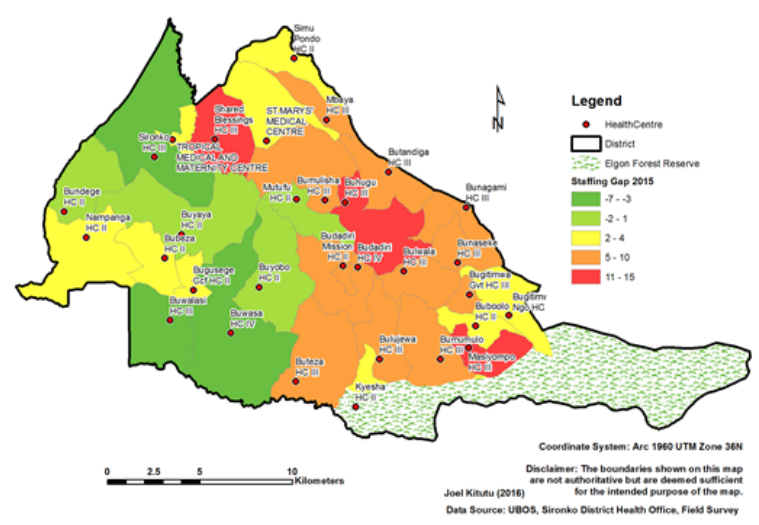

Legend

$0 \quad$ HealthCentre
$\square$ District
$\square=2$ Elgon Forest Reserve

Minimum Staffing (HSSIP)

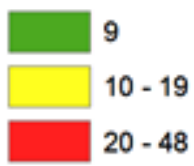

Figure 5. Health Facility Staffing Gap
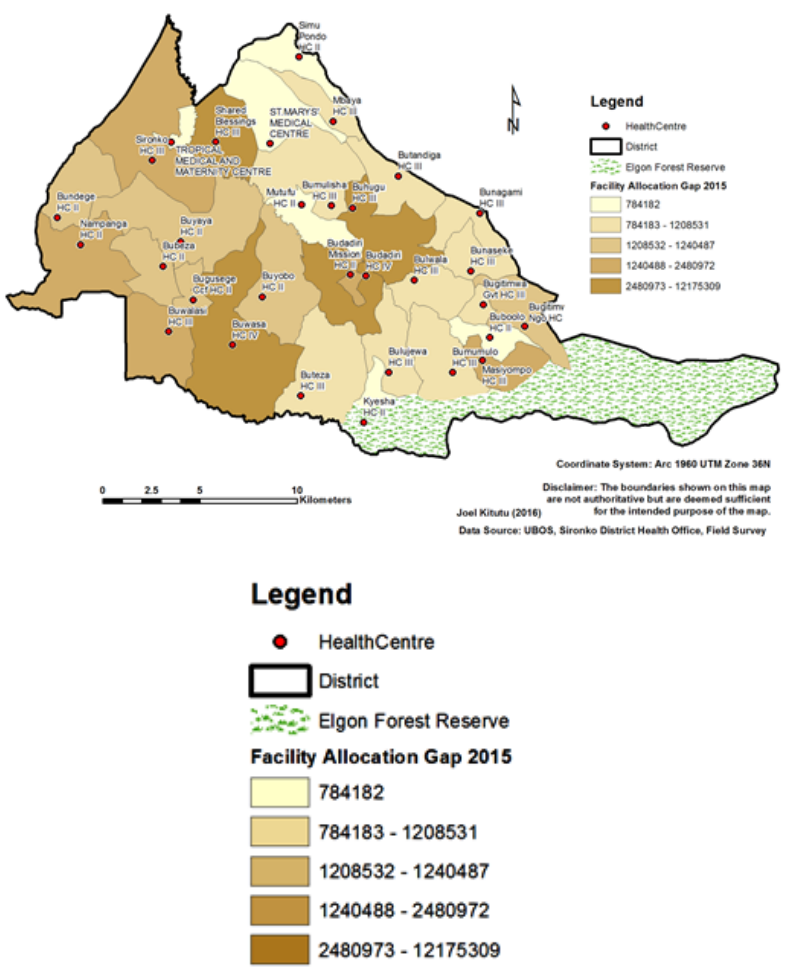

Figure 4. Health Facility Allocation Gap

Map of Sironko District Health Centre Highest Stockout Days

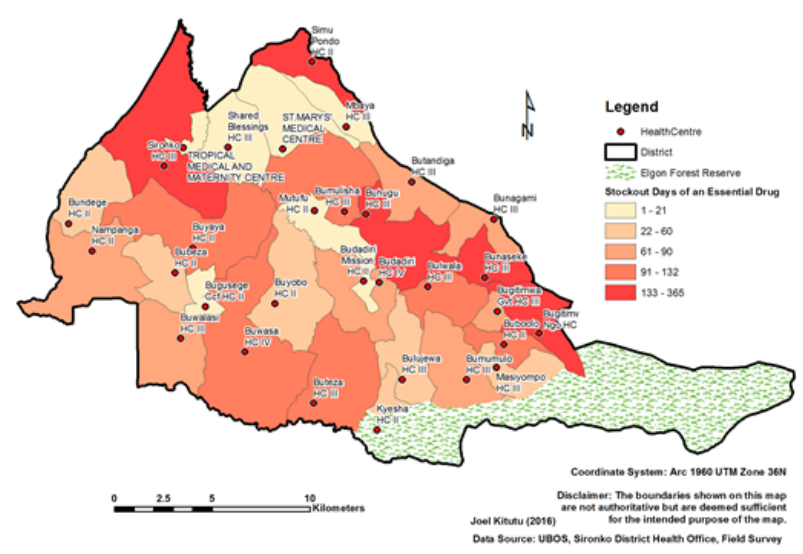

Legend

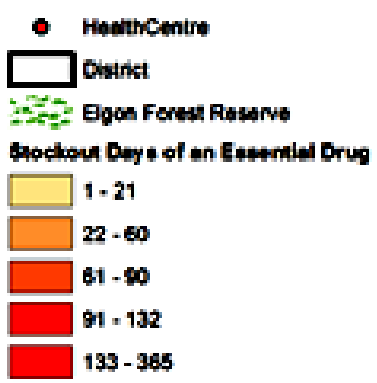

Figure 6. Health Centre Highest Stock-Out

Days 


\subsection{Regression Results}

Figure 7 shows the Over and Under-Predictions from GWR. Large over and under predictions can be seen in the central part of the district i.e. Buwasa HC IV, Bumulushi HC III and Buyobo HC II. The over and under predictions indicate the areas whose OPD figures for the produced regression model varied most significantly in the positive and negative directions respectively. From visual analysis, the over and under predictions were generally randomly distributed indicating an acceptable regression model had been produced. Furthermore, Figure 8 show the results of Global Moran's I test performed on the standard residuals to statistically affirm the randomness of the distribution implying that the regression model performance was good. Unlike in the work of Evangelos et al. (2015) where no significant relationship was found between the independent and predictor variables, this regression results showed existence of relationship between the used variables.

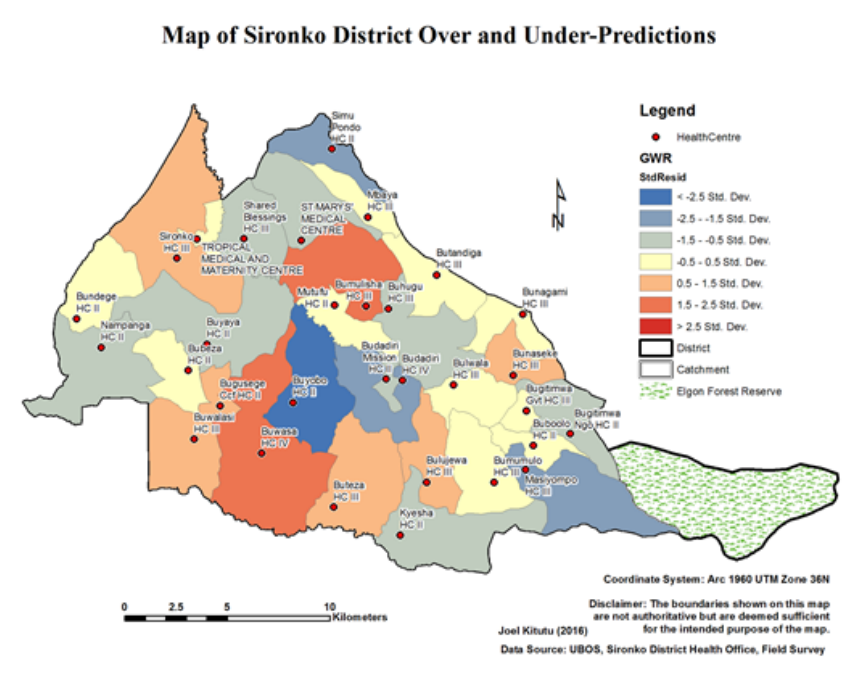

\section{Legend}

- Healthcentre

GWR

StdResid

$\square<-2.5$ Std. Dev.

$-2.5=1.5 \mathrm{std}$. Dev.

ए $-1.5--0.5$ Std. Dev.

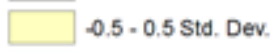

$0.5-1.5 \mathrm{Std}$. Dev.

$1.5-2.5$ Std. Dev.

$>2.5 \mathrm{Std}$. Dev.

$\square$ District

Catchment

zEz Elgon Forest Reserve

Figure 7. Over and Under predictions from GWR

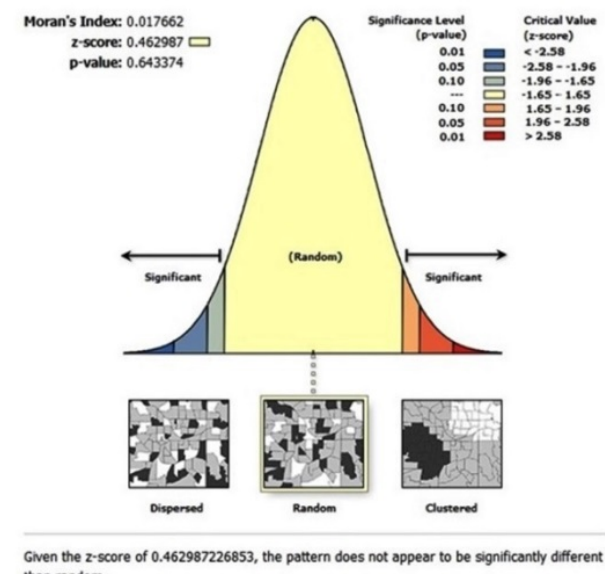

Given the r-scored

Moran's Index: 0.017662

z-score: $0.462987 \square$

p-value: 0.643374

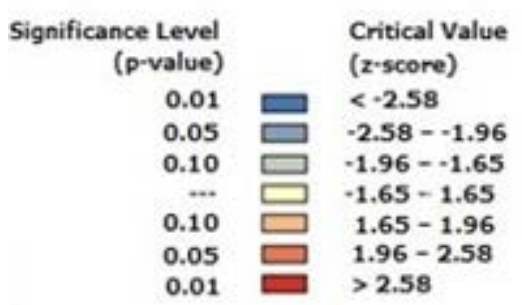

Figure 8. Results of Global Moran's I test performed on the standard residuals 
Table 3 shows the major GWR model attributes which include; observed and predicted OPD attendance numbers, the residuals and standardized residuals, the y-intercept, coefficients of the independent variables, and the local R-squared values for individual local models for health centres in the study area.

Table 3. GWR model attributes

\begin{tabular}{|c|c|c|c|c|c|c|c|c|c|}
\hline HC_NAME & Obsv. & Pred. & Resid. & $\begin{array}{c}\text { Std } \\
\text { Resid } \\
\end{array}$ & $\begin{array}{c}\text { Inter } \\
\text { cept } \\
\end{array}$ & $\begin{array}{c}\text { C1 } \\
\text { FAGAP }\end{array}$ & $\begin{array}{c}\text { C2 } \\
\text { STFGAP } \\
\end{array}$ & $\begin{array}{c}\text { C3 } \\
\text { SODH } \\
\end{array}$ & LocalR2 \\
\hline Bubeza HC III & 4079 & 3626 & 453 & 0.1455 & 5785.4493 & 0.003 & -1200.3156 & -20.015 & 0.9217 \\
\hline Buboolo HC II & 4814 & 5421 & -607 & -0.1854 & 5699.7829 & 0.0008 & -90.5471 & -5.8539 & 0.0973 \\
\hline Budadiri HC IV & 16307 & 18944 & -2637 & -2.1282 & 8199.876 & 0.0014 & -1021.6127 & 27.0766 & 0.6119 \\
\hline Budadiri Mission HC II & 2469 & 4881 & -2412 & -0.7902 & 8439.8982 & 0.0013 & -928.1842 & 21.0913 & 0.5661 \\
\hline Bugitimwa HC II NGO & 5381 & 6212 & -831 & -0.2226 & 5668.3874 & 0.0008 & 15.0237 & -7.7758 & 0.1826 \\
\hline Bugitimwa HC III & 1627 & 4734 & -3107 & -1.1363 & 5157.0071 & 0.0003 & -4.1321 & -3.7874 & 0.0193 \\
\hline Bugusege HC II & 7158 & 5814 & 1344 & 0.5367 & 4555.905 & 0.0028 & -1094.5804 & 8.0695 & 0.915 \\
\hline Buhugu HC III & 3094 & 4593 & -1499 & -0.9239 & 9296.8705 & 0.001 & -632.5768 & 5.2157 & 0.4334 \\
\hline Bulujewa HC III & 11233 & 6565 & 4668 & 1.323 & 7793.2924 & 0.0013 & -421.7886 & 4.1577 & 0.4397 \\
\hline Bulwala HC III & 7911 & 6529 & 1382 & 0.3694 & 6720.9155 & 0.0009 & -64.2854 & -8.9939 & 0.3492 \\
\hline Bumulisha HC III & 15404 & 8117 & 7287 & 1.9832 & 9259.7308 & 0.0011 & -614.9858 & 5.4622 & 0.2934 \\
\hline Bumumulo HC III & 7468 & 6334 & 1134 & 0.2953 & 6317.0213 & 0.0011 & -108.9309 & -6.4215 & 0.2664 \\
\hline Bunagami HC III & 9017 & 7315 & 1702 & 0.4999 & 7338.6591 & 0.0006 & 61.2392 & -13.2373 & 0.2699 \\
\hline Bunaseke HC III & 6689 & 4689 & 2000 & 0.8191 & 6254.1253 & 0.0007 & 108.655 & -11.6532 & 0.2415 \\
\hline Bundege HC II & 6098 & 6615 & -517 & -0.1931 & 4920.5607 & 0.0038 & -1254.6399 & -28.9933 & 0.8448 \\
\hline Butandiga HC III & 8267 & 7987 & 280 & 0.0795 & 10651.002 & 0.0008 & -631.7079 & 1.7846 & 0.3761 \\
\hline Buteza HC III & 11636 & 8457 & 3179 & 1.2906 & 8204.8578 & 0.0015 & -1221.7986 & 61.8284 & 0.7813 \\
\hline Buwalasi HC III & 18619 & 16993 & 1626 & 1.0876 & 6236.4799 & 0.0026 & -1450.2603 & -0.9797 & 0.9555 \\
\hline Buwasa HC IV & 48104 & 46538 & 1566 & 1.9934 & 3213.8426 & 0.0022 & -1190.0298 & 77.5338 & 0.9186 \\
\hline Buyaya HC II & 6823 & 8571 & -1748 & -0.6622 & 4373.3461 & 0.0028 & -814.2016 & 5.9858 & 0.8127 \\
\hline Buyobo HC II & 54 & 8777 & -8723 & -2.71 & 5007.882 & 0.002 & -1164.4413 & 44.9737 & 0.7834 \\
\hline Kyesha HC II & 4293 & 6198 & -1905 & -0.8344 & 5311.528 & 0.0015 & -182.9301 & 11.2524 & 0.367 \\
\hline Masiyompo HC III & 1132 & 2677 & -1545 & -1.5543 & 6971.9387 & -0.0003 & -225.2517 & -8.5416 & 0.1542 \\
\hline Mbaya HC III & 8964 & 7636 & 1328 & 0.4067 & 9691.9922 & 0.001 & -536.352 & -4.5668 & 0.1636 \\
\hline Mutufu HC II & 10022 & 8619 & 1403 & 0.4289 & 7997.6798 & 0.0014 & -825.2095 & 17.7126 & 0.4914 \\
\hline Nampanga HC II & 4420 & 5834 & -1414 & -0.6375 & 8011.0144 & 0.0029 & -1608.1525 & -52.5031 & 0.9201 \\
\hline Shared Blessings & 1349 & 2033 & -684 & -0.8098 & 6948.0176 & 0.0022 & -771.0037 & 4.7423 & 0.6095 \\
\hline Simu Pondo HC II & 5126 & 6047 & -921 & -2.1795 & 8669.1404 & 0.0019 & -707.8376 & -5.3849 & 0.2625 \\
\hline Sironko HC III & 17761 & 16850 & 911 & 0.9642 & 4837.3008 & 0.0033 & -900.5202 & 1.7393 & 0.8704 \\
\hline St. Mary's Medical C. & 5126 & 7814 & -2688 & -0.9166 & 8666.3361 & 0.0017 & -717.3653 & -1.7121 & 0.3534 \\
\hline Tropical Medical C. & 5126 & 5251 & -125 & -0.0508 & 5536.8527 & 0.0029 & -848.7284 & 4.2344 & 0.8003 \\
\hline
\end{tabular}

The relationships between the OPD visits and each of the three predictor variables were mapped on scatter plots to reveal their nature and strength. Figure 9 shows a steep positive slope indicating a strong positive relationship between OPD visits and facility allocation gap in a health facility. Figure 10 shows a steep negative slope indicating a strong negative relationship between OPD visits and 
health staffing gap in a health facility. Figure 11 shows a very small positive slope indicating a weak positive relationship between OPD visits and highest stock-out days in a health facility.

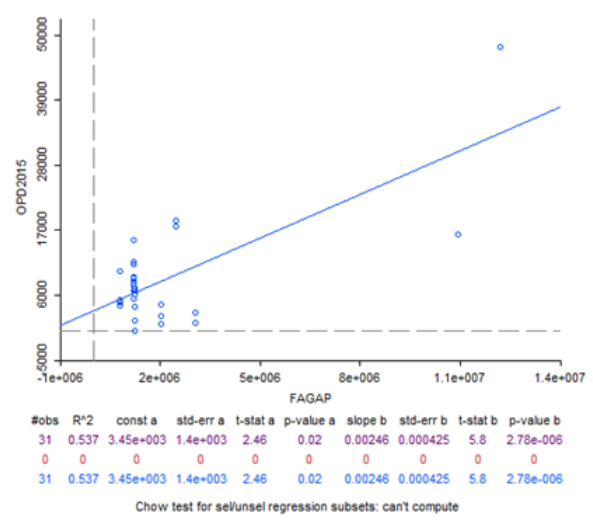

Figure 9. OPD visits versus Facility Allocation Gap

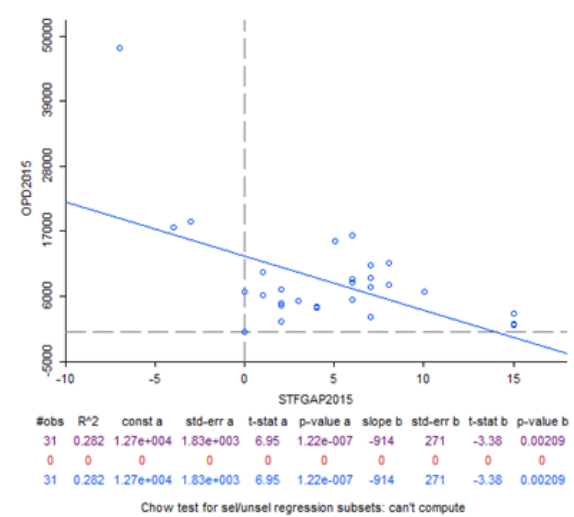

Figure 10. OPD visits versus Staffing Gap

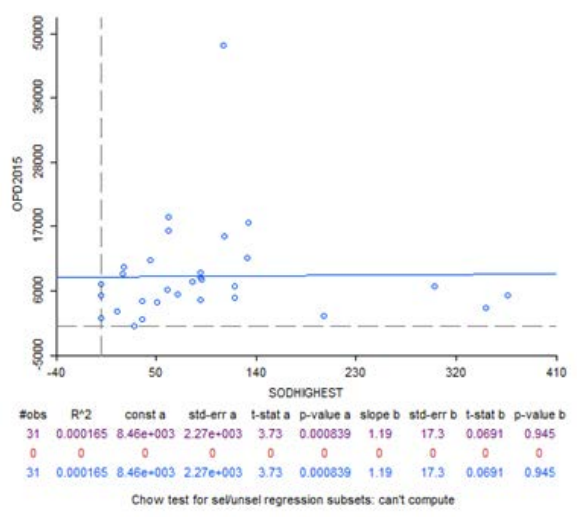

Figure 11. OPD visits versus Highest Stock-Out days for an essential drug in a Health facility

\subsection{Local Parameter Variation}

The output of the regression analysis yielded local parameter estimates which were mapped to reveal the spatial variation of the relationships (Matthews et al., 2012). Figure 12 shows strong influence of Facility Allocation Gap in the North West which diminishes towards the South East. This direction is from the low lying town areas towards the remote mountainous side. This suggests such areas of strong influence on the model and high population should have more health funds budgeted for as compared to other areas considering a limited health vote for the district. Figure 13 shows stronger negative influence of the staffing gap in the South West which diminishes Eastwards. This direction is from the plains to the mountainous areas in the East. With attention on the less subtractive influence on the model (i.e. weaker negative influence), government's providence of better incentives for health workers in the remote mountainous areas could see a significant reduction in the staffing gaps. In figure 14, there is a very high influence of Stock-Out days in the South of the district as compared to the South West. These same areas exhibit fairly high Stock-Out days. Such areas should have the supply and dispensing of essential drugs examined to reveal the actual causes of high StockOut days in the Health Centres. 

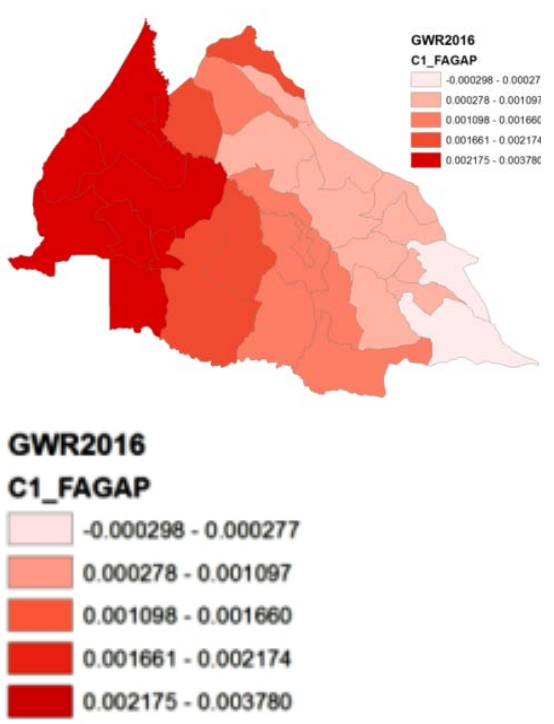

Figure 12. Coefficients(C1) for Facility Allocation Gap
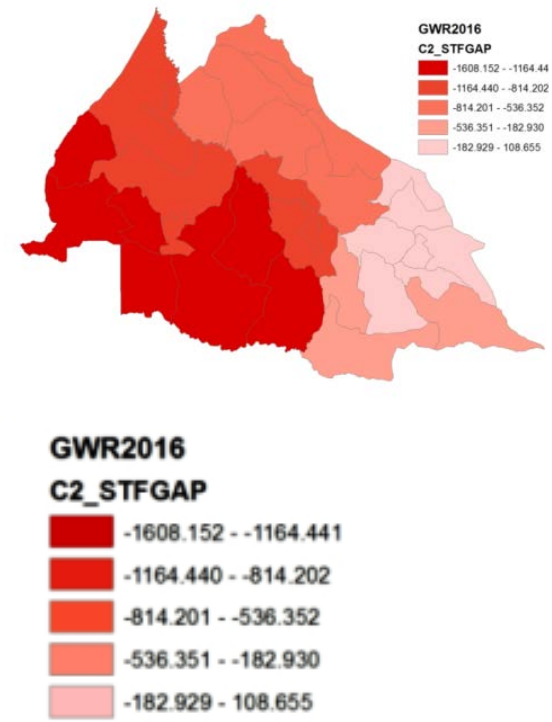

Figure 13. Coefficients(C2) for Staffing Gap
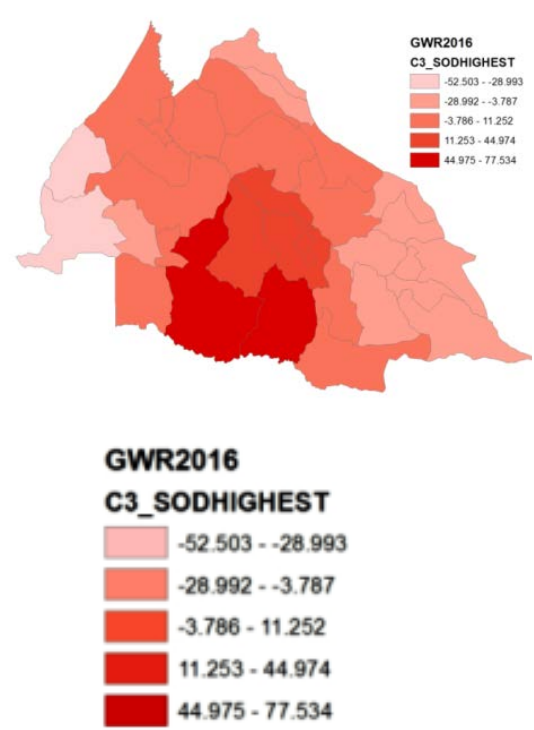

Figure 14. Coefficients(C3) for Highest Stock-out days

\subsection{Health Policy}

The Second National Health Policy of Uganda states that the government of Uganda prioritizes research especially the kind that is geared towards guiding the development and implementation of health systems. The policy furthermore provides for the sharing of information between all stakeholders in the health sector, researchers inclusive; the kind of information that is relevant to the needs of the people and consistent with HSSPs. The policy advocates for optimal level of all necessary health resources, medicines, finance and the strengthening of human resource through attraction, proper motivation and remuneration, all which are key to an efficient and effective health system. The Health Policy thus lays a good foundation but one that is not adequately informed in terms of procedure for prioritization and distribution of the minimum healthcare package. The previous analysis (section 4.4) coupled with the following key observations indicate both general and specific propositions informing the health policy for its improvement. 
4.6. Policy Propositions

Table 4. Key observations made within the study area

\begin{tabular}{|c|c|c|c|c|}
\hline Variable & $\begin{array}{l}\text { Health } \\
\text { Centre } \\
\end{array}$ & Observation & Interpretation & Policy Proposition \\
\hline \multirow[t]{2}{*}{ SOD } & $\begin{array}{l}\text { Buhugu } \\
\text { III, } \\
\text { Bugitimwa } \\
\text { NGO II }\end{array}$ & $\begin{array}{l}\text { High SOD } \\
\text { (More than } 100 \\
\text { days, of an } \\
\text { essential drug) }\end{array}$ & $\begin{array}{l}\text { Severe Stock out, Need to check } \\
\text { supply of drugs and monitor utilization }\end{array}$ & $\begin{array}{c}\text { Increase monitoring of supply of } \\
\text { drugs }\end{array}$ \\
\hline & $\begin{array}{l}\text { Sironko } \\
\text { III, } \\
\text { Buwasa } \\
\text { IV, Buteza } \\
\quad \text { III }\end{array}$ & $\begin{array}{l}\text { High OPD, } \\
\text { High SOD }\end{array}$ & $\begin{array}{l}\text { High OPD could explain High SOD, } \\
\text { need to supply sufficient drugs based } \\
\text { on catchment population and utilization } \\
\text { as compared to budgetary allocation }\end{array}$ & $\begin{array}{l}\text { Drug distribution should be } \\
\text { based on need and not on } \\
\text { budgetary allocation of funds }\end{array}$ \\
\hline \multirow[t]{2}{*}{ FAG } & Buhugu Ill & $\begin{array}{l}\text { Low OPD, } \\
\text { High FAG }\end{array}$ & $\begin{array}{l}\text { High FAG could explain low OPD, } \\
\text { need to allocate more funds for better } \\
\text { services that can cater for more patients }\end{array}$ & \multirow{2}{*}{$\begin{array}{l}\text { Increase the health vote and } \\
\text { prioritize district allocation } \\
\text { based on need (OPD) and not on } \\
\text { level of Health Facility }\end{array}$} \\
\hline & $\begin{array}{l}\text { Buwasa } \\
\text { IV, } \\
\text { Budadiri } \\
\text { IV }\end{array}$ & $\begin{array}{l}\text { High OPD, } \\
\text { High FAG }\end{array}$ & $\begin{array}{l}\text { Facility Allocation is inversely } \\
\text { proportional to OPD, need to increase } \\
\text { Facility allocation to cater for the high } \\
\text { OPD }\end{array}$ & \\
\hline STFGAP2015 & Masiyopo & $\begin{array}{l}\text { Low OPD, } \\
\text { High } \\
\text { STFGAP2015 }\end{array}$ & $\begin{array}{l}\text { High STGAP2015could explain low } \\
\text { OPD, also other factors could explain } \\
\text { high STGAP2015e.g. towards the } \\
\text { mountain (farther from town, hard to } \\
\text { reach areas), Staffing gap is high }\end{array}$ & $\begin{array}{l}\text { Increase staffing and provide } \\
\text { incentives (e.g. belier housing } \\
\text { and pay) for hard to reach areas }\end{array}$ \\
\hline
\end{tabular}

Table 4 shows key observations that were made within the study area, their interpretations and some policy propositions that could help in ameliorating the healthcare situation in Sironko district.

\section{Conclusion}

From the study, it was observed that indeed great disparities existed in health funding, staffing and supplies especially in the hard-to-reach mountainous areas of Sironko district. This calls for government to provide incentives for health workers in these areas and gradually increase the provision of the much-needed resources. The heterogeneous nature of patterns of healthcare indicators through Sironko district show the need for area specific solutions derived to mitigate the health challenges of the different regions of the district. With complete data consistently collected periodically for all the health facilities, better models can be generated to underpin efforts to diminish the health challenges faced within the district. The current health policy shows goodwill towards the alleviation of challenges related to healthcare service delivery. However, it is essential to inform the policy through geostatistical analysis as it's evident that public health and geography are inseparably linked. An improved health system will thus better the lives of the people in Sironko district and inevitably lead to sustainable development. 


\section{Acknowledgement}

We would like to thank the Ministry of Health, Uganda Bureau of Statistics, and Sironko District Health Office for the valuable data that they provided for this study. Sincere gratitude goes to the health officers at the health centres that were visited during the facility survey. Their input ably informed this study.

\section{References}

Alka, P 2012, Evaluating Geographic Access to Cardiac Catheterization Facilities to Inform Regionalized Models of Care for Acute Myocardial Infarction, , pp. 151, viewed 22 December 2016, <http://theses.ucalgary.ca/bitstream/11023/198/2/ucalgary 2012 patel alka.pdf >

Amer, S, 2007, Toward Spatial Justice in Urban Health Service Planning: A spatial-Analytic GIS-based approach using Dar es Salaam, Tanzania as a case study, International Institute for Geoinformation Science and Earth Observation (ITC), Enschede, The Netherlands, pp. 284

Anselin, L 1995, Local indicators of spatial association-LISA, Geographical analysis 27(2), pp. 93-115

Brunsdon, C, Fotheringham, AS, \& Charlton, ME1996, Geographically weighted regression: A method for exploring spatial nonstationarity, Geographical Analysis 28(4), pp. 281-298, viewed 26 December 2016, $<$ http://eprints.maynoothuniversity.ie/5895/1/CB_Weighted\%20Regression.pdf>

Chi, G., \& Zhu, J., 2016, 'Southern Demographic Association Spatial Regression Models for Demographic Analysis’, Population Research and Policy Review, vol. 27, pp. 17- 42

Fotheringham, A, Charlton, M \& Brunsdon, C 2001, 'Spatial Variations in School Performance: a Local Analysis Using Geographically Weighted Regression’, Geographical and environmental Modelling, vol. 5, no. 1, pp. 43-66

Hazrin, H, Fadhli, Y, Tahir, A, Safurah, J, Kamaliah, MN \& Noraini, MY 2013, 'Spatial patterns of health clinic in Malaysia’, Health, vol.5, No.12, 2104-2109, viewed 17 November 2016, <http://dx.doi.org/10.4236/health.2013.512287>

Homan, T, Malar, J, Maire N, Hiscox, A, Pasquale, AR, Kiche, I, Mweresa, C, Mukabana, WR, Ross, A, Smith, TA, Onoka, K, \& Takken, W 2016, 'Spatially variable risk factors for malaria in a geographically heterogeneous landscape, western Kenya: an explorative study’, Malaria Journal, vol. 15, no. 1, pp. 8

Kontopantelis, E, Springate, DA, Ashworth, M, Webb, RT, Buchan, IE \& Doran T 2015, 'Investigating the relationship between quality of primary care and premature mortality in England: a spatial wholepopulation study’, viewed 28 December 2016, <http://dx.doi.org/10.1136/bmj.h904>

Lin, CH \& Wen, TH 2011, 'Using Geographically Weighted Regression (GWR) to Explore Spatial Varying Relationships of Immature Mosquitoes and Human Densities with the Incidence of Dengue', International Journal of Environmental Research and Public Health, vol. 8, pp. 2805

Matthews, S. \& Yang, T., 2012, 'Mapping the results of local statistics: Using geographically weighted regression, Demographic Research, vol. 26, pp. 160, <http://doi:10.4054/DemRes.2012.26.6>

Matthews, SA, \& Yang, TC, 'Mapping the results of local statistics: Using geographically weighted regression', viewed 27 December 2016, <https://www.ncbi.nlm.nih.gov/pmc/articles/PMC4286400/> 
Ministry of Finance, Planning and Economic Development 2013, Budget Monitoring and Accountability Unit (BMAU) Briefing Paper (10/13), The Health Sector Budget: Trends in levels of financing, composition and use, pp. 1

Ministry of Health 2015, Annual Health Sector Performance Report for Financial Year 2014/15, pp. 19-20

Nakaya, T., Fotheringham, A.S., Brunsdon, C., \& Charlton, M., 2005, ‘Geographically weighted Poisson regression for disease association mapping', Statistics in Medicine vol. 24(17), pp. 2695-2717, $<\underline{\text { http://doi:10.1002/sim.2129> }}$

Pirdavani, A., Bellemans, T., Brijs, T., \& Wets, G., 2014, ‘Application of Geographically Weighted Regression Technique in Spatial Analysis of Fatal and Injury Crashes', vol. 1, pp. 1-26, $<$ http://doi.org/10.1061/(ASCE)TE.1943-5436.0000680>

Rhee, K., Kim, J., Lee, Y., \& Ulfarsson, G. F., 2016, 'Spatial regression analysis of traffic crashes in Seoul. Accident Analysis and Prevention’, vol. 91, pp. 190-199, <http://doi.org/10.1016/j.aap.2016.02.023> Sinaga, K. P., Hutahaean, M., \& Gea, P., 2016, 'Spatial Variation in Infant Mortality with Geographically Weighted Poisson Regression (GWPR) Approach’, vol. 5(3), pp. 96-100

WHO 2000, The Abuja Declaration: Ten Years On, 2001 Promises of commitment and solidarity, pp. 1, viewed 11 September 2016, < $\underline{\text { www.who.int/healthsystems/publications/Abuja10.pdf> }}$

World Health Organization 2010, Monitoring the building blocks of health systems: a Handbook of indicators and their measurement strategies, pp. 3, viewed 11 September 2016, <www.who.int/healthinfo/systems/WHO_MBHSS_2010_full_web.pdf>

Young, L.J. \& Gotway C.A., 2010, 'Using geostatistical methods in the analysis of public health data', The final frontier geoENV VII - Geostatistics for Environmental Applications, vol. 16, pp. 89-98,

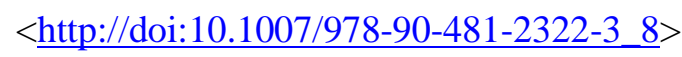

